\title{
Research on the Development of Art Design and Fashion Industry
}

\author{
Mengqi Wang ${ }^{1, a}$, Xinqun Feng ${ }^{1, b}$ \\ ${ }^{1}$ School of Donghua University \\ Shanghai 200051, China \\ a253393461@qq.com, b451496289@qq.com
}

\begin{abstract}
Along with the progress of China's economy, the fashion industry has gradually emerged, and the professional quality of its practitioners in the rising process is directly related to the future direction of this industry. This will need to strengthen the development of the fashion industry and promote the progress of the fashion industry. This paper aims to explain for fashion, and further explores the interaction between fashion industry and professional development, under the final detailed explores the professional art design for the fashion industry development in China.
\end{abstract} talent

Keywords-Fashion industry; College education; Creative

\section{INTRODUCTION}

Since the reform and opening up, with China's economic and social progress, people gradually overstating the requirements for the standard of living, fashion industry has been able to appear and progress. Fashion can be called creativity, is in a certain period of time by some people first practice, and after the forecast will become the public favorite and imitate the style. From its definition can be seen, fashion is also the concept of time and advocate the interaction between the two concepts. From the literal point of view, fashion is also a certain period of time within the people advocate lifestyle, it is integrated into the different areas of life, such as basic necessities, and even including the emotional performance and thinking patterns and other fields. With the above-mentioned areas are closely related to the industry has become a fashion industry. From the connotation of consideration, fashion is a personal or some organizations use different symbols, signs show the phenomenon; from the aesthetic point of view, fashion is in a certain period or period by a specific social and cultural background of the designer Created or show the picture, but also from the clothing and other decorative areas to guide the trend and fashion; from the consumer's point of view to consider, the most simple fashion show is looking very beautiful. At the same time, people's understanding of the connotation of fashion is also constantly changing. The twentieth century, the eighties, when people may feel that Pierre Cardin or Montagut led the fashion at the time; and early into the twenty-first century, Gucci or LV brand may lead the time Fashion, and since the beginning of the decade, the term "fashion" has begun to cover the cultural connotations covered by the top brands and the changes in areas such as people's lifestyles. And lifestyle changes, but also continue to act on people in all areas of basic necessities. At the same time, fashion professional with this change into the university, which has become the inevitable trend of fashion development.
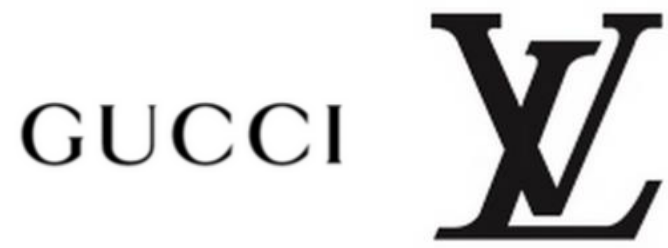

Fig. 1 The Brand logo of GUCCI and LV

\section{THE FASHION INDUSTRY GAVE BIRTH TO A FASHION PROFESSIONAL}

\section{A. The development of fashion industry}

Fashion industry progress, covering the electronics field, clothing and even luxury goods and other fields. The need for designers who have created and designed in many creative areas has increased, so there has been a growing number of colleges and universities that have recently developed courses to develop professionals and enter this fast-growing industry. For example, Tianjin University of Technology put the image of the professional design of the College of Continuing Education as a new professional, which is the first professional in the public full-time colleges and universities to carry out. In addition, China University of Geosciences opened the creation of the Institute of Jewelry, has also become China's first set up gemological education professional institutions of higher learning, and this college since the establishment of the present, has helped China's related industries to cultivate a number of gemology High professional quality of talent, has become China's "treasure cradle", gemological education is not only to identify the gem material grade, this specialty is geology, materials science and other different disciplines under the interaction Of the product, in the tourism, trade and even banks and other fields, the professional high-quality talent can play its role, while this gem professional contact jewelry consumption of the luxury market, which has become a key component of the fashion industry [1]. 


\section{B. Fashion industry driven by the fashion professional}

Fashion industry spawned out of the fashion profession, which is now booming creative design is essentially the same. Only the creative design can continue to produce fashion products, can promote the fashion industry's continuous progress. Britain's creative design field, each year to help the economy in this area to $12 \%$ increase in speed, the US creative design is as high as $14 \%$, from the proportion of creative industries in fact has gradually developed into a developed country Pillar industry. Considering from a global perspective, creative industries can even generate an average of nearly \$22 billion a day, and this amount is increasing at an annual rate of five percentage points. All of the above figures have made us more clearly understand that the value of the creative industry and the designers of the industry has a key role in the development of the fashion economy and the cultural industry. In some developed countries, the art design profession of colleges and universities is often followed by the progress of the market and constantly changing, especially for the practice of practice, so the construction of these countries related to the design of art is more mature, and almost completely tight With the requirements of industrial development [2]. And China's fashion industry is relatively backward, and even a long period of time only as the same time to install the relevant design industry exists. In the world, many related theories are in the study of the University under the current social background and the role of global economic progress under the change and innovation, has not yet recognized the new concept of fashion industry, the emergence and progress of cognitive Backward and the lack of relevant designers has become China's fashion industry continues to improve obstacles, but also directly hindered the University of the relevant art and design of a higher level of professional construction, hindering the University to cultivate the cultural industry to adapt to the situation of talent.

\section{THE CURRENT PERIOD OF CHINA'S FASHION INDUSTRY DEVELOPMENT}

In the current period, many colleges and universities in China are facing the cultural industries that have flourished, and have made great efforts to promote the progress of the local economy. They have created a lot of practical experience in art design. Facing the development direction of cultivating talents who meet the requirements of the local fashion industry, we must have the characteristics such as the keenness and openness of education in the field of art and design, and make use of the current advanced education and teaching concept, Adhere to enhance the ability of students in the guiding ideology, in the discipline construction continue to implement the practice and sum up experience combined with the concept of the relevant disciplines to build to achieve change, and then enhance the relevant professional and technical training results, nurture and provide adapt to the trend of fashion industry talent, Promote the level and extent of development.

\section{A. Overview of cultural and creative industries}

On the one hand, many universities for art design discipline construction is more perfect. Fashion is actually a fashion led by a fashion, so the cultural industry has become a key industry supporting the fashion industry, which is the cultural and creative industries is a key part of the cultural industry, a period of time, cultural and creative industries in the process of economic globalization More and more critical position. According to the different categories of cultural and creative industries in different countries of the world, at the same time drawing on the classification of industry in China, we can divide our cultural and creative industries into four categories: one is culture and art, as the name suggests, The third is the media industry, covering all aspects of the media, such as publishing, film, television and other aspects; the fourth is the IT industry, covering all aspects of the media, such as the design, such as architectural design, costume design, etc. .; the third is the media industry, covering all aspects of the media, Industry, the focus is on the computer aspects of the content [3].

\section{B. Cultural and creative industry development}

As we can see above, the art and design profession covers almost all aspects of the cultural and creative industries. In our country, to enhance the progress of the creative industry will be the future trend. According to specific data, 12 years ago, Shanghai has 18 creative industries base, from 2005 to 2008, three years to 50 growth. And in Beijing is a six key cultural and creative training base. In the cultural and creative industries of high-speed progress now, but also need to rely on the university's educational resources, cultivate cultural and creative industries must be the key talent.

\section{WITH THE RESOURCES OF COLLEGES AND UNIVERSITIES, CULTIVATE CREATIVE INDUSTRIES RELATED PERSONNEL}

\section{A. The way to cultivate creative talents in colleges and universities}

In the teaching of the university, the teaching model into a more interactive, enhance the level of practice of students to study the practice of integration is the practice of integration approach. First, teachers need to first enter the market, to build students can practice the environment and atmosphere. That is, from the market to get back with some of the students to carry out the course content of the project. In the teacher's lead, to promote students to the theoretical level of learning can be carried out in the relevant classroom practice, although not into the community, but still able to contact the industry market, enhance the practice of students operating level. Second, enhance the professionalism of teachers themselves. On the one hand is to promote teachers "going out". Art design in this profession, its content and related knowledge update rate is higher than other professional, which must be constantly updated by the teachers of those new knowledge and ideas. Therefore, it is necessary to regularly appoint teachers in this area to a higher level of the school to learn, to receive more close to the market knowledge. On the other hand is the teacher "please come in". To those who have entered the industry for many years, with more experience of designers, entrepreneurs please go to school to help students understand the specific needs of the market, and thus provide more employment opportunities, in addition to the elite teachers can be introduced to the school, the advanced 
teaching Concepts and solutions to the key situations encountered in learning to teach teachers and students, to promote teachers and students to update their ideas. Third, the face of the design must be closely related with the characteristics of the market, continue to adjust and improve the professional curriculum system, curriculum design, the need to closely focus on market demand.

\section{B. Cultivate brand awareness}

In the process of marketing, the brand is as a business behavior exists. From the development of the situation to consider, reduce the market fluctuations in the process of changes in its profits, compared to other commodities, reducing market risk, and thus promote the enterprise to obtain more profits. Students in the school can not have the identity of the enterprise, in order to achieve the process of school began to try to create a brand, and then enter the community constitute the brand of sublimation and transformation, to practice in the campus model. Art design students can be free to team up to achieve this creation, the school needs to support. During the school, different creative teams compete with each other, with the brand to create, the key is conducive to the school's own needs, moderate contact with the community, and then achieve a smooth operation, and slowly accumulate experience. For example, after the entrepreneur out of the school after the survey shows that many entrepreneurs since leaving school, practice, until they have the ability to independent portal, developed to have their own fame, regardless of the middle of the case by the market to abandon the case, which Successful cases also need more than ten years to reach the level of minor celebrities. But from the previous considerations, advocated to improve the teaching methods of teachers to create the school "market" to lead students no longer confined to the campus but into the social and other ways to build since the students initially entered the school to carry out practical " Learning, research, listing "model, and then promote students to have a higher initiative to adapt to the learning and internship environment, to promote them as possible to comply with market rules, and then their business cycle as short as possible to promote economic progress faster[4].

\section{Popularization and development of art design education}

Artistic design education has been an important symbol of the rapid progress of all aspects of the country's economic and social development. More than 20 years ago, the British Prime Minister Margaret Thatcher once thought that Britain could lose the government, but could not lose its design. Japan, South Korea also began to promote "design to save the country." For example, the design of the mobile phone style: Samsung Group with attractive design in just ten years to develop into a world famous brand. Nokia has a close relationship with the well-known design institutes in many countries around the world, and in 2004, it spent a lot of money working with many universities around the world, which covered the China Academy of Fine Arts, Nokia's new models of the image, and thus overcome the Nokia mobile phone can not adapt to different countries of different aesthetic issues. The creative industry's need for talent covers the creative design associated with the culture, which includes animation design and so on. These aspects are part of the art design, and the progress of the creative industry will certainly make for the design of talent the promotion of the request. Therefore, the current university for the construction of art and design is the industry at the same time the real progress of the industry has a very close relationship with each other to help each other. We must clearly understand this relationship, can more calmly face the fashion creative industry for the relevant design talent requirements, and thus continue to promote the progress of the fashion industry.

\section{$\exists \times \supset \exists$ वTIOH de MIXMIND}

Fig. 2 The fashion Brand

\section{CONCLUSION}

Comprehensive above, for the current society for the new direction of the development of fashion industry, has become the needs of China's fashion industry, but also become the academic focus of the current university art. This kind of inquiry can not only promote the development of academic, more critical is to develop teachers and students of the horizon, so as to promote the common progress of science and art, from the more profound aspects of the relevant education and theoretical research. Therefore, we must understand and strengthen the scientific and harmonious links, which for the construction of creative talents in China base is very critical.

\section{REFERENCES}

[1] Western Quality Education .2017 (05) [J]. Journal of East China Normal University (Philosophy and Social Sciences Edition)

[2] Wu Chujun. Analysis of China's art and design education [J]. Art Education Research .2016 (22)

[3] Wang Pu. Art design education system reform [J]. Journal of Xinxiang Education College .2015 (01)

[4] Huang Yongjian. China's higher artistic design education concept comparison and thinking [J]. Modern decoration (theory) $2016(03)$. 